\title{
WATER QUALITY MANAGEMENT: CAN WE IMPROVE INTEGRATION TO FACE FUTURE PROBLEMS?
}

\author{
László Somlyódy \\ International Institute for Applied Systems Analysis \\ Laxenburg, Austria \\ and \\ Budapest University of Technology \\ Budapest, Hungary
}

RR-96-13

September 1996

Reprinted from Water Science Technology, Volume 31, No. 8, pp. 249-259, 1995.

INTERNATIONAL INSTITUTE FOR APPLIED SYSTEMS ANALYSIS

Laxenburg, Austria 
Research Reports, which record research conducted at IIASA, are independently reviewed before publication. Views or opinions expressed herein do not necessarily represent those of the Institute, its National Member Organizations, or other organizations supporting the work.

Reprinted with permission from Elsevier Science Ltd, The Boulevard, Langford Lane, Kidlington OX5IGB, UK.

Copyright (C)1995 IAWQ

All rights reserved. No part of this publication may be reproduced or transmitted in any form or by any means, electronic or mechanical, including photocopy, recording, or any information storage or retrieval system, without permission in writing from the copyright holder.

Printed by Novographic, Vienna, Austria. 


\section{Foreword}

Water is likely to be a severely stressed resource in the next century. Problems are becoming increasingly complex and diverse and are occurring on a larger scale and with time-lag effects. Many different, site-specific quantity and quality issues appear simultaneously, and thus no global policy can be developed. These features call for improved cooperation among various disciplines, sectors, countries, and societies.

This paper discusses observed and likely future trends in water quality management, pitfalls and barriers, and lessons learned, and identifies the most important challenges facing water quality managers. It is hoped that the thoughts presented here will contribute to the identification of future water-related research at IIASA now that the study of water quality management in Central and Eastern Europe has been completed.

Peter E. de Jánosi

Director 


\title{
WATER QUALITY MANAGEMENT: CAN WE IMPROVE INTEGRATION TO FACE FUTURE PROBLEMS?
}

\author{
László Somlyódy \\ International Institute for Applied Systems Analysis, A-2361 Laxenburg, Austria \\ and \\ Budapest University of Technology, Müegyetem rkp. 3, H-1111 Budapest, Hungary
}

\begin{abstract}
Water (and its deteriorating quality) may be the most severe stress on the exponentially growing human population in the next century. Problems are becoming increasingly complex and diverse and require more and more specific knowledge, and efficient integration across various disciplines, sectors, countries, and societies. The major challenge addressed is whether we are prepared to realize the desired integration and to resolve the large amount of existing gaps and barriers. The paper analyzes major past and desired future trends in water quality management. A number of issues are selected such as the identification, occurrence, and perception of various problems (e.g. eutrophication, acidification, global warming), pollution control types, wastewater treatment, modeling and monitoring, planning and environmental impact assessment, legislation and institutions, the notion of sustainable development, and the role of science and engineering. The past two decades showed tremendous developments in water quality management. In spite of these, the focus of the present discussion lies mostly on pitfalls to disseminate lessons and questions which are crucial to likely future problems and desired improvements.
\end{abstract}

\section{KEYWORDS}

Central and Eastern Europe; control types; developing world; EIA; global trends; institutions; integration; international water resources; legislation; modeling; monitoring; planning; river basins; science and engineering; sustainable development; wastewater treatment; water quality management.

\section{INTRODUCTION}

Water quality comprises all the properties of water besides its quantity. In practice, it is given by a large number of physical, chemical, biological, and other parameters. The actual characterization of water quality is never unambiguous; dominating parameters depend on uses (such as domestic, industrial, agricultural, recreational, and others), problems (hygiene, oxygen, household, eutrophication, salinization, acidification, toxics, etc.), space and time, and the subjective judgement of the analyst which cannot be excluded. Water quality management is a commonly used and somewhat vague expression referring to the (systematic) usage of a set of technical and non-technical measures and activities, to maintain or improve quality according to the requirements of water uses and to "protect" ecosystems.

Water quality management is at the interface of water resources management and environmental management, which draws from hydrology, biology, chemistry, ecology, engineering, economics. and 
other sciences and disciplines. Accordingly, there is a broad range of professionals who deal with quality issues such as sanitary, water resources, environmental, and other engineers, hydrologists, limnologists, biologists, chemists, economists, and so forth. In other words, the field is rather broad and there is not a unique profession which could have "ownership." The often used notion of river basin management stresses that the natural scale of water resources management is a river basin from the point of view of both quantity and quality, which is frequently forgotten in practice. Finally, "integration" expresses the desire to look for the "totality" of the management problem.

Water quality issues are becoming more and more complex and diverse. The handling of these issues requires an increasing amount of specific knowledge on the one side and more efficient integration across various disciplines, emissions, sectors, countries, cultures, and societies on the other side. These two requirements seem to be rather contradictory. Thus, the major challenge which we address here is whether we are really prepared to realize the wished integration in theory and practice, alike.

\section{OBSERVED AND FUTURE DESIRED TRENDS}

It is often said that water is a limited valuable resource (freshwater resources form less than $1 \%$ of the total water in the Globe, $85 \%$ of use is for irrigation) essential to life which behaves rather differently than other elements of the biosphere. There is not really a global or unified strategy on how to handle the variety of problems of different scales (see Fig. 1) which may appear, often jointly depending on the geographic location. This is probably one reason why the "Brundtland report" (WCED, 1987) - and the 1992 UNCED conference - overlooked the "water issue" (for example, see Biswas, 1992a), which may have the most severe stress on human population in the next century.

Fresh water degradation is a consequence of the overall socio-economic development which took place after the Industrial Revolution. Population pressure is a key element of the water dilemma (the wish for improved standard of living adds another component of the problem). Population grows exponentially, and it may exceed 10 billion by the end of the next century (for example, see UN, 1989). Most of the increases will occur in developing countries. As shown by Kulshreshtha (1993), a ten times greater proportion of the population than today may be negatively affected by water "scarcity" already in 2025 . A significant uncertainty stems from the poor understanding of possible impacts of climate change on quantity and quality alike. Urban population was nearly doubled between 1970 and 1990 and in the next twenty years it may reach 3.7 billion (Niemczynowicz, 1992), while rural population seems to stabilize (UN, 1989). The world's fastest growing and largest cities are located in the lowest income countries and are characterized by a low level of water infrastructure and wastewater treatment. The provision of water supply and sanitation would require strikingly high costs: on the order of 300 to 400 billion USD by 2000 (Niemczynowicz, 1992). By 2025, the urban population of developing countries will almost equal the world's total population in 1975. It is estimated that around $30 \%$ of this urban population could be living in cities of more than four million people. In Central and Eastern Europe (CEE), under the present political, social, and economic transition, high municipal emissions due to past non-sustainable infrastructure developments form one of the most serious problems and require heavy investments (Somlyódy, 1994). In the developed world, the emerging need to rehabilitate aged infrastructure causes a problem; the seriousness of this problem is not yet recognized. All these statements stress that urban pollution management forms one of the biggest challenges of the coming decades.

In the developed world, there is a gradual shift towards non-point source pollution control. The growing number of chemical toxicants entering the environment (annually about 10000 new organic compounds are synthesized, Wetzel, 1992) form a vast problem: even detection capabilities are lacking (in spite of developments in analytical chemistry), and harmful effects are largely unexplored. Central and Eastern Europe is characterized by the co-existence of point and non-point source issues as well as traditional and toxic pollutants. Unlike arguments which suggest that problems in the developing world are similar to those in Europe 150 years ago, the low income countries face (or will soon) all the pollution problems of agricultural, industrial, and urbanization origins simultaneously; this is not a promising perspective.

Subsequent to this rather sketchy overview on water problems in different regions of the world with different levels of development, Fig. 1 and Table 1 (taken with some modifications from Somlyódy et al., 
1992) will serve as the basis for our further discussion. They illustrate changes in major features of pollution issues as well as the ways we handle them (mostly in the developed world). Some of the general trends (Fig. 1) - increasing scale of problems, delayed and irreversible environmental responses, growing role of non-point source emissions, unforeseen interactions among different pollutants and media, "surprises", etc. - are observed today, and they are likely to be continued. In this sense, there may not be a sharp difference among past, present and future, and for the sake of simplicity in Table 1 we indicate only "past" and "future". The changes of several attributes cannot be really prognosticated and thus Table 1 often indicates desired orientations. Also, many features of future quality issues are unknown and uncertain as was the case in the past (could we have fully foreseen the present state of water quality management say twenty years ago?)

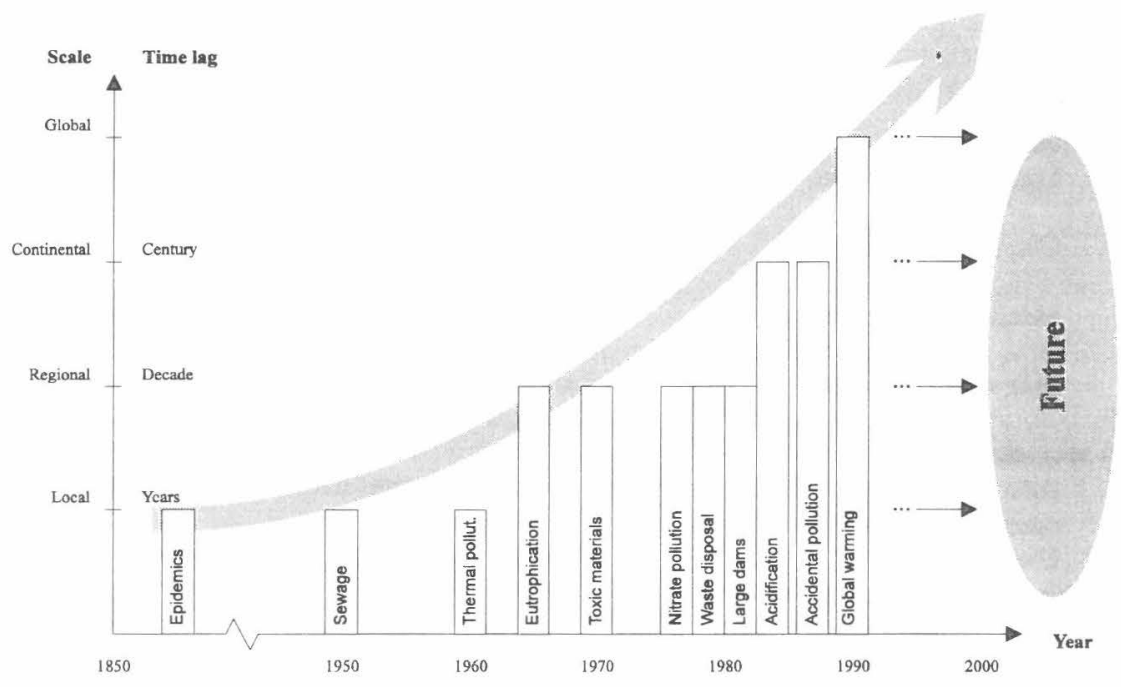

Figure 1. Trends in pollution problems.

Many of the alterations summarized in Fig. 1 and Table 1 are well known (for example, see Meybeck and Helmer, 1989; Wetzel, 1992). Thus it is not our intention to offer a comprehensive discussion, rather - as noted before - we will focus on a number of issues characterized by many developments and shortcomings, alike. Our focus will mostly lay on pitfalls in order to disseminate lessons and questions (following the structure of Table 1) which can be important when "speculating" on likely future problems and desired improvements.

\section{CHALLENGES}

\section{Problem Identification, Occurrence, and Perception}

Figure 1 illustrates the approximate time when a given problem was recognized by professionals and management actions were launched extensively. However, it is striking to realize the huge gaps between the scientific identification of a potential problem, the first observational indications, the perception by the professional community, public, and decision makers, and the development of response measures (see Döös, 1991). For instance, the greenhouse gas issue, acidification, and eutrophication all were identified as likely future problems one hundred years ago or so. In spite of this, no preparations were made for a long time to tackle the above issues, although the basic knowledge was not missing. 
Table 1 . Trends in water quality management

\section{PAST}

FUTURE

\section{(1) Control Type}

"End of the pipe"

Technical

\section{(2) Treatment}

"Traditional technology"

\section{(3) Monitoring}

Local measurements

Conventional parameters

Monitoring of water

Poor data availability

\section{(4) Modeling}

Individual issues (processes, control, operations, planning, etc.)

Use by experts

(5) Planning and Project Evaluation

Poor/narrow definition of objectives

Short-term view

Cost evaluation

Little concern on failures and adjustment needs

(6) Science and Engineering

Science does not drive actions

Problem isolation and engineering solutions

Interdisciplinary gaps and barriers

(7) Legislation, Decision Making Institutions and Development

General rules and rigidity

Fast implementation (a misbelief)

Little enforcement

Command and control

Confusing institutional settings

Decisions by politicians and

administration

National policies
Source control, closing material cycles, land use management, concern on large scale projects

Non-technical elements

Reuse and recycling

Special treatment methods (biologicalchemical treatment, upgrading, natural treatment, small-scale treatment) and emerging new traditions

Networks, remote sensing, continuous measurements

Special parameters (eco-toxicology, biomonitoring, etc.)

Integration of effluent and ambient monitoring and environmental monitoring Improved availability (data bases, digital maps, telecommunication)

Integration (model library, DSS, GIS, expert systems, etc.)

Use in administration, meetings, etc.

"Sensible" definition

Long-term view

EIA, risk and multiobjective evaluation, social and political impacts

The future is never certain: reliability, resiliency, robustness, and vulnerability

\section{"Science for Action"}

Improved planning

Integration of quantity, quality, hydrology, and management

Specific rules and flexibility

Process view

Improved enforcement

Polluter (and user) pays

Clearer structures and less barriers

Public awareness and participation, NGOs, and enhanced communication

International policies

Sustainable development: how to proceed? 
Reasons for this lag can be manifold. First, we can generalize the statement of the U.S. National Research Council (1991) from the hydrologic science to environmental sciences: "science has followed rather than led the applications" (Table 1). In fact, environmental and water quality management is primarily driven by crises, accidents, and interest groups. Countermeasures and corrections are made nearly exclusively when the problem is already there and action should be made immediately. "Problems are accepted and treated, rather than prevented," states Wetzel (1992). Secondly, management needs appear if the concern is serious (crisis was certainly not the case around the turn of the century for the above mentioned three issues). Thirdly, it is unclear even today how scientists can express their management views effectively such that they have an impact on applied research fields, engineering, and decision making alike.

We may continue the example with eutrophication and the seventies. At that time, lake eutrophication was a widely recognized phenomenon, and successful restoration programs were also known (based on sewage phosphorus control). Still, there was little concern about the impact of increasing fertilizer application ("diffuse pollution" was identified later as an issue), the construction of drinking water reservoirs fed by river waters of high $\mathrm{P}$ concentration (which then often led to "surprisingly" poor trophic states and related water treatment problems), eutrophication of rivers in downstream reaches or impounded stretches of increased residence times (many European rivers exhibit annual peak chlorophyll-a values close to or above $200 \mathrm{mg} / \mathrm{m} 3$ which would characterize a hypertrophic state in lakes), or the continental nutrient enrichment problems of rivers and inland seas (for example, the Baltic or the Black Sea in Europe).

While the first part of the example shows that science has little impact on policies, the alarming conclusion of the second portion is that applied sciences and engineering are not significantly better off in enhancing prevention of a likely problem.

\section{Pollution Control: From "End of the Pipe" Towards Prevention}

In the Western world, much progress has been made in monitoring and controlling point source emissions. As noted, the focus is shifting towards diffuse loads and control at the source (Table 1). The realization of this thrust is not easy in practice. Reasons are manifold. Traditional non-point source control requires rather different legislation and incentives than employed in the past. The stress should be on controlling activities and the application of materials of possible harmful impacts, which calls for the integration of water quality management, land use management, and regional development.

Source control and the intention to close material cycles face lots of barriers even under relatively "welldefined" cases such as urban areas. The unbalanced water infrastructures in many urban areas (characterized by decreasing capacities of water supply, collection network, wastewater treatment, and sludge handling), the unnecessarily high water consumption and wastewater treatment needs due to subsidies and unrealistic water prices (undervaluing), aged networks, and the lack of re-evaluating the application of seemingly successful traditional methods (see later) are some of the reasons leading to opened water and material cycles. For instance, a recent survey on municipal infrastructure in the CEE region (Poland, the Czech Republic, Slovakia, Hungary, and Bulgaria, see Somlyódy, 1994) showed that on average $90 \%$ of the population is connected to public water supply. However, the percentage of connection to sewerage is not more than $70 \%$ (in some countries, only $50 \%$ ), while biological treatment is less than $50 \%$ of the collected wastewater (of an average BOD removal rate not more than $70 \%$ ). Finally, only part of the sludge produced is adequately disposed (perhaps not more than $50 \%$, but it is difficult to estimate). $\mathrm{N}$ and $\mathrm{P}$ cycles are nearly fully open.

The above features are mostly associated with confusing and weak institutional arrangements. Water demand management has a long tradition, and advanced methods are available for planning. However, supply, demand, and the waste generation side are usually handled independently in planning, operation, and management alike.

When invented, the flush toilet was an innovation to reduce diseases and pests. But today, we question whether 10-15 litres of water (per flush) used essentially as a transport vehicle is not too much as it significantly increases wastewater treatment costs $(1 \mathrm{~m} 3 / \mathrm{d}$ capacity requires roughly 500-1000 USD capital cost for a medium sized plant). Or another question: should we use a unified supply system in 
houses serving high quality water although an order of magnitude less would be sufficient? Should we focus on better controlling the water cycle on the household level? Or another rarely addressed question: do we always need large collection systems forming the largest cost component of an urban water infrastructure? Would it be wise - depending on the actual situation - to consider also on site treatment, infiltration, and other non-conventional tools (and their mix with the traditional collection-treatment systems with a focus on impacts on groundwater; see Novotny and Olem, 1994)? More generally, how and when should we change a good tradition which may lead to undesired future developments? Or differently stated, how do we avoid the repeated and exclusive usage of methods we were "taught at the university" without asking why we use just this way of problem solving? How do we avoid using inappropriate technologies and find appropriate ones?

We know that the raising of the above issues seems naive for existing systems. But how would we develop the infrastructure of a fully new settlement or city today? How about fast growing towns and forthcoming rehabilitation? Which policy should and could be followed in underdeveloped rural areas and developing countries?

Until now, we touched upon traditional diffuse pollution and "urban metabolism". These are relatively simple issues in comparison to "industrial metabolism". As Stigliani (1990) and Lohm (1992) pointed out, an efficient abatement of chemical pollutants requires accounting for flows of manufactured chemicals through the economy and the society. Actually, in addition to point and diffuse emissions, a consumption related emission (through dissipation and disposal) should be also defined. There is evidence (for instance, for $\mathrm{Cr}$ in Sweden and Cd in the Rhine watershed) that with point source control, not only diffuse pollution but also consumption emission has an increasing importance (the situation should be similar for a variety of chemicals in many regions). The latter one depends on (among others) raw material import and consumption pattern, broadening again significantly the scope of water quality and environmental management. The recognition of the importance of industrial metabolism is an important notion, but the dilemma is - like with sustainability (see later) - whether or not we can use it in an operational sense for action.

\section{Wastewater Treatment}

Wastewater treatment forms the roots of water quality management. Biological and chemical treatment have a history of about a century. Biological processes became dominating in wastewater treatment (except for instance in the Scandinavian countries), while chemical methods are in widespread use in water treatment (in combination with physical and other processes in both cases). The recognition of multiple pollutant problems and other issues (process optimization, improved design, etc.; see Hahn, 1990), led to the slow combination of the two methodologies. For instance, chemical addition is an obvious choice to remove phosphorus and heavy metals (for industrial pre-treatment and control at the source) and to increase the capacity of existing overloaded biological plants with primary clarifiers with low investment (which is an important issue today in the CEE region; see Somlyódy, 1994). However, biological processes cannot be excluded if nitrification and denitrification are considered. In turn, there is also an increasing need in water treatment for combining the two different processes, whenever nitrate contamination is an issue.

The above, frequently desired combination often meets with difficulties. Professionals, manufacturers, and legislators sometimes believe in the exclusive application of one of the methods, and communication is far from being satisfactory. The arguments against chemicals are still the increased amount of sludge (in spite of achievements of low dosage methods) as well as the fear of chemicals as such. Ironically, the application of biological denitrification at water plants is objected to sometimes because of possible public health implications.

As mentioned, wastewater treatment is the most traditional element of water quality management. In spite of this, there is little communication between treatment engineers and those who deal with receiving waters. Usually design takes place on the basis of effluent standards, and thus the analysis of basin wide water quality impacts (including emissions of different origins) and various control strategies (depending on water quality goals, financial conditions, and cost recovery these can be important considerations in the 
CEE region and in the developing countries) may remain fully excluded. The gap is further illustrated by the present state of modeling on the two interrelated fields: although many achievements have been made in modeling carbon and nutrient removal by treatment plants (see the IAWPRC activated sludge model; Henze et al., 1987) and cycling in rivers and lakes (for example, see Thomann and Mueller, 1987), there are hardly two such models which would use the same water quality variables (and fractionation) and thus could be linked to each other.

\section{Modeling and Monitoring}

Developments in information and computer technology, electronic communication, remote sensing, instrumentation, control, and modeling have already had a significant impact on our profession (comprising research, operation, planning, EIA, decision making, etc.). Combining databases (including on-line monitoring and areal information), models, and interfaces, i.e. the development of decision support systems (for example, see Fedra and Loucks, 1985; Fedra, 1993), offers earlier unthinkable opportunities of integration, analyses, and the consideration of complex water and environmental problems (Table 1).

This trend will continue, but still there are a number of alarming symptoms. First, it appears that the development of computer technology far exceeds the present opportunities of data collection and experiments. Second, rather old fashioned models are often used in "fancy" packaging - there may not be enough focus on developing new ideas and methodologies. Third, with increasing sophistication, the checking of the accuracy of results becomes more and more important, and the knowledge of the analyst remains a crucial factor. Fourth, the communication gap between "modelers" and "non-modelers" is not diminishing to an extent we would like to see it, which clearly raises educational issues.

There is also a schism between data collectors and analysts (as stated by the U.S. National Research Council, 1991, for hydrology): "the pioneers of hydrology" (and our profession) "were active observers and measurers, yet now, designing and executing data collection programs (as distinct from field experiments with a specific research objective) are too often viewed as mundane or routine" which leads to an "erosion" of such programs. The analysis adds, "modeling and data collection are not independent processes. Ideally, each drives and directs the other. Better models illuminate the type and quantity of data that are required to test hypotheses. Better data, in turn, permit the development of better and more complete models and new hypotheses. We must reemphasize the value and importance of observational and experimental skills."

Country wide water quality monitoring is a common practice all over the world. The major objectives (frequently non-specified) are the description of the "state of the water environment" and the causes of changes, trend detection, estimation of annual (or monthly) average loads, and the derivation of certain statistical parameters for water quality classification, and so forth. But are these monitoring systems well and economically designed? Are the obtained data utilized satisfactorily? For instance, is the error of estimating averages and percentile values if the sampling frequency is fixed (often on the basis of intuition) analyzed? Is it recognized that trend detection is often an impossible task (or the probability of the estimate is unacceptably low) if the likely trend is small, the variance is high, or the time series is strongly autocorrelated (Somlyódy et al., 1986)? Why are we rarely monitoring emissions and ambient quality simultaneously? All these are disappointing questions calling for future improvements.

\section{Planning and Environmental Impact Assessment}

Water resources planning and EIA processes (see Table 1) are unavoidable when considering large scale problems and projects of possible serious impacts. The related literature is vast, even for developing countries (for example, see Ebisemiju, 1993). Well-known schemes identify subsequent steps of the procedure such as the specification of goals, objectives and constraints, definition of alternatives, screening, evaluation of impacts (economic, environmental, social, cultural, political etc.), selection and decision making, implementation, monitoring, and modification, if desired.

There are a number of success stories in planning and EIA (which was first introduced in 1969 in the U.S.). On the contrary, there are cases where problems stem from failure to apply the above 
methodologies. Obvious examples come from the pre-EIA era (for instance the Aswan Dam) as well as from the developing world and the CEE region where the related culture is still weak. For instance, in the developing world, less than $10 \%$ of the countries have an established (for about ten years) EIA framework and the performance is rather disappointing. As stated by Ebisemiju (1993), the gap between the intent and performance is attributed to legislative, administrative, institutional, and procedural reasons much more than technical ones. Frequently, the assessment is made at a postscript stage only for a single "alternative" already decided upon. The practice was rather similar in the earlier socialist countries.

Some of the pitfalls come from incorrect definition of goals and objectives (like the mistaken estimation of future demands), the overlooking of some of the impacts (several dam projects exhibit this undesirable feature), and the lack of the integration of the assessment into the entire project cycle. The EIA guidelines, checklists, matrices, etc., are very useful, but a "too strict" application of them can lead to overlooking the most critical consequences. The monitoring after implementation and adjustment possibilities are often missing, or more importantly, correction needs are rarely admitted. To have an earlier decision altered - even if there have been significant changes in our knowledge and the actual conditions in the meantime - is one of the most difficult achievements.

Certainly, there are also a number of evaluation difficulties even in relatively simple cases. It suffices to refer to projects where, on the economic side, costs play the decisive role: the availability or lack of the starting investment costs and the assumption on the interest rate automatically makes the task multiobjective in character. The issue becomes much softer as soon as we incorporate benefits in terms of water uses and protecting aquatic life (not including social, aesthetic, and other implications). While perhaps the first one can still be defined, the second one is non-quantifiable, and it really depends on public awareness and willingness to pay. We can systematically organize the pros and cons, but the final decision will largely depend on subjective arguments of participants involved in the procedure.

Many of the infrastructure investments are particularly difficult to evaluate. These issues are frequently political in nature, and decisions strongly depend on the priorities of politicians in power. To attract tourists, investors, cheap loans, to create new enterprises, to stabilize economy and society, and so forth, are frequent arguments used.

Projects often raise serious conflicts which are hard to evaluate. Dams and human-constructed reservoirs are recognized as a source of emerging conflicts between the economy and the environment, between different branches of water management (for example, see Kundzewicz, 1993), and possibly between different countries (such as the Slovakian-Hungarian dispute on the Gabcikovo-Nagymaros barrage scheme on the Danube). At present, the views on such projects are rather extreme: what we need is a forum to discuss positive and negative experiences collected to set a future agenda on how to proceed.

Water and environmental scientists/engineers face the dilemma of solving problems of tomorrow today. Risk and uncertainty logically receives increasing attention (Table 1). New concepts and notions have been introduced such as robustness, reliability, resilience, and vulnerability (see Hashimoto et al., 1982) to characterize the value of today's decisions on an uncertain future. Although real life applications are not yet known, it is hoped that related methodological innovations will lead to improved planning and assessment in the future.

\section{Legislation and Institutions}

Engineers are sometimes accused of narrowly considering defined sub-problems which lead to failures in environmental and water quality management since the sum of these solutions may not be equivalent with that of the entire issue. This and similar statements raise a number of questions. What is the scale and scope of a problem engineering can tackle? Whose responsibility is to decompose problems into tractable pieces? The answer to the last question is systems analysts, planners, or generalists. But where are they acting? In principle, legislation and institutions should be developed such that they self-evidently lead to proper problem handling. However, it is rarely the case, and poor legislative and institutional settings cause much mismanagement. 
The difficulty of water quality management starts with the fact that impacts and benefits are frequently hard to identify (for example, see Thomann, 1972), and thus "efficiency" analyses are often considered of low value. The consequence in the developed world is that legislation is based mostly on three assumptions: (i) to set generalized effluent standards (relying upon the "best available technology") such that ambient quality will be good "all the time", (ii) economic conditions are sufficient to realize such a safe policy, and (iii) the principle of "equity" leading to uniform emission reduction (which may be significantly more expensive than a regional least-cost policy).

Such an approach led to a number successful applications. However, in the U.S. for instance, the number of water bodies not meeting water quality goals is appreciable after completing point source control programs. The reason is diffuse pollution most of the time and the failure to consider all the emissions and ambient quality impacts jointly (separated by effluent criteria). The ongoing revision of the Clean Water Act (passed in 1972) looks for a more "holistic" approach focusing strongly on river basins (which was not the case before), watershed wide planning and management, non-point sources, and economic implications (Novotny and Olem, 1994).

The future is by all means towards integrated land use-water management policies. But how can we realize it if we considered the huge amount of existing institutional shortcomings, mismanagement, and administrative barriers (for example, see Moss, 1992; Falkenmark, 1992)? "The administrative infrastructure basically mirrors the scientific divisions, " according to Falkenmark (1992) - or the isolation is perhaps even stronger. Water and environmental regional authorities have very little controlling role on economic activities (agriculture, industry, tourism, housing development, etc.) in the given region (and even they are in conflict with each other in countries where both operate), and various interest groups and lobbies often play an overruling role. How can we integrate water management under fragmented conditions when different aspects of water (health, quality, pollution from various sectors, quantity, etc.) all belong to different ministries in the administration?

Management of water quality confronts many more obstacles in the developing world than in industrialized countries (see Hamza, 1992). Missing or inadequately developed legislation, institutions, standards, economic instruments, monitoring, enforcement, unclear institutional responsibilities, and the overall lack of financing form perhaps the most significant barriers (Table 1). Concepts to develop appropriate standards, economic instruments, technology, and financing schemes are absent. These are perhaps enough arguments to come back to related ideas of water management (Thomann, 1972) rarely utilized in the industrialized world and to re-think how to proceed. A similar statement applies to most of the earlier socialist countries where although knowledge exists, financial constraints will remain a significant problem in the course of coming decades (see Somlyódy, 1994).

With increasing water scarcity and pollution problems (of growing scale, see Fig. 1), international, transboundary issues become more and more important, which makes the entire setting more complex. As pointed out by Biswas (1992b), information available on such problems is outdated, and we cannot identify the real magnitude of the issue. "What perhaps is needed is an International Law of the Hydrologic and Biogeochemical cycles" mentions Moss (1992) when discussing issues of global environmental change. But can it ever be realized?

\section{Sustainability}

Trends in development and environmental problems, notions of prevention, source control, consumption emission, closing of material cycles, cross-sectoral and other, improved integration, etc., self-evidently lead to needs which are expressed by sustainability. At least two questions emerge. Is it more than one of the many buzzwords which we cannot really define? Can we use it operationally?

The best-known and probably most widely used definition of sustainable development was given by the WCED (1987) as "development that meets the needs of the present without compromising the ability of future generations to meet their own needs" (see Peet, 1992). Peet adds correctly, "this definition is so general ... there is a real danger that sustainability as a goal will lose its credibility." And later, he writes, "the Brundtland definition may be better than nothing for as long as there is nothing better". 
Referring to de Vries, he states, "Sustainability is not something to be defined, but to be declared. It is an ethical guiding principle."

We tend to agree that sustainability is "an ethical guiding principle" which is hard to make operational (certainly, this principle may influence the definition of goals and objectives of a particular project, i.e. it can have an indirect impact on planning). We also believe that sustainability will have a broader impact than earlier principles (like "environmentally sound management"). The reason probably lies in the increasing recognition of environmental issues by the public and politicians and the much more aggressive (in a good sense) and broader publicizing of the principle than in the past for other ideas. Still, about a decade ago, the prevailing attitude was that technical progress will take care of the problems we create. There appears to be a shift in thinking towards more cautious, longer term behavior and a less optimistic attitude.

Still, the question "how to do it?" remains open. For instance, the related action program of the European Community (CEC, 1992) summarizes rather general guidelines. The purpose is to provide "a framework for a new approach to the environment and to economic and social activity and development, and requires positive will at all levels of the political and corporate spectrums, and the involvement of all members of the public active as citizens and consumers in order to make it work". We think that improved education from kindergarten onwards and improved integrated planning are one set of crucial prerequisites to realize slowly the new "guiding principle." Stable economies and stable societies form another, even more important pre-condition. But how can we achieve them for most of the population?

\section{CLOSING REMARKS}

The title of the paper identified a question which then led to many more detailed ones which we are unable to answer. Historical development of water resources management has shown a shift in focus from quantity to quality issues. The increasing role of non-point sources, toxic contamination, large scale, multiple pollutant and multiple media problems, the recognition of consumption emissions and global changes as a whole will alter this tendency. It is unlikely that quantity and quality can be handled separately any more. A much stronger integration of hydrology (the water cycle), the biogeochemical cycle, water resources management, land use management, and water quality management is required (Table 1). In a broader sense, this integration should comprise also environmental management, technology, development, and society. Tremendous gaps and barriers should somehow be overcome. Gaps between existing and used knowledge, lack of future visions supported by science, gaps between different disciplines and professions, barriers in legislation, institutions, and decision making, lack in communication are just a few examples.

Our profession cannot exist without scientists and engineers. Their activity is driven by questions and answers, respectively. They have to remain in their own fields preserving (improving) their strength. What is needed is probably more "science for action" and a stronger focus on how complex problems can be split into tractable pieces to be handled by engineers and professionals, i.e. improved analysis and planning. The slogan "think globally, act locally" expresses well the dilemma we face. Whether we can handle it, remains to be seen.

\section{ACKNOWLEDGEMENT}

The author is indebted to Olli Varis from the Technical University of Helsinki for his thoughtful comments and motivating discussions while working on this paper.

\section{REFERENCES}

Biswas, A. (1992a). Water for Third World Development: A Perspective from the South. Water Resources Development, 8(1), 3-9.

Biswas, A. (1992b). Management of International Water: Problems and Perspective. In: Transboundary River Basin Management and Sustainable Development: Proceedings, J.-C. van Dam and J. Wessel (Eds), Vol. I, $31-42$.

Commission of the European Communities (CEC), (1992). Towards Sustainability, Vol. II. 
Döös, B. R. (1991). Environmental Issues Requiring International Action. RR-91-16, International Institute for Applied Systems Analysis, Laxenburg, Austria.

Ebisemiju, F.S. (1993). Environmental Impact Assessment: Making it Work in Developing Countries. Journal of Environmental Management, 38, 247-273.

Falkenmark, M. (1992). Possibilities for Sustainable Development: Adapting the Desirable to the Possible. In: Transboundary River Basin Management and Sustainable Development: Proceedings, J. -C. van Dam and J. Wessel (Eds), Vol. I, 211-223.

Fedra, K. (1993). Expert Systems in Water Resources Simulation and Optimization. In: Stochastic Hydrology and its Use in Water Resources Systems Simulation and Optimization, J.B. Marco et al. (Eds), 397-412.

Fedra, K. and Loucks, D. P. (1985). Interactive Computer Technology for Planning and Policy Modelling. Water Resources Research, 21, 114-122.

Hahn, H. H. (1990). Quo Vadis Chemical Treatment? In: Chemical Water and Wastewater Treatment, H. H. Hahn and R. Klute (Eds), Springer-Verlag, Berlin, 1-14

Hamza, A. (1992). Water Quality Monitoring in the Developing World: Challenges and Prospects. In: Proceedings: A Holistic Approach to Water Quality Management Finding Life-Styles and Measures for Minimizing Harmful Fluxes from Land to Water, Stockholm Water Symposium, 63-96.

Hashimoto, T., Loucks D. P. and Stedinger, J. R. (1982). Reliability, Resiliency, Robustness, and Vulnerability Criteria for Water Resource Systems. RR-82-40, International Institute for Applied Systems Analysis, Laxenburg, Austria.

Henze, M., Grady, Jr, C. P. L., Gujer, W., Marais, G. V. R., Matsuo, T. (1987). Activated Sludge Model No. 1. IAWPRC Task Group on Mathematical Modelling for Design and Operation of Biological Wastewater Treatment, IAWPRC, London, England.

Kulshreshtha, S. N. (1993). World Water Resources and Regional Vulnerability: Impact of Future Changes. RR-93-10, International Institute for Applied Systems Analysis, Laxenburg, Austria

Kundzewicz, Z. (1993). Conflicts Between Environmental and Water Resources Issues. ECO Newsletter: Environmental Conflicts, 1(3), 4-7.

Lohm, U. (1992). Predicting Harmful Fluxes Through Analysis of Industrial Metabolism. In: Proceedings: A Holistic Approach to Water Quality Management Finding Life-Styles and Measures for Minimizing Harmful Fluxes from Land to Water, Stockholm Water Symposium, 157-166.

Meybeck, M. and Helmer, R. (1989). The Quality of Rivers: From Pristine Stage to Global Pollution. Palaeogeography, Palaeoclimatology, Palaeoecology (Global and Planetary Change Section), 75, 283-309.

Moss, B. (1992). Uses, Abuses and Management of Lakes and Rivers. Hydrobiologia, 243/244, 31-45.

Niemczynowicz, J. (1992). A Call for Realistic Alternatives for the Future. Impact of Science on Society, Environment and Development, UNESCO No. 166, 1992, 131-147.

Novotny, V. and Olem, H. (1994). Water Quality: Prevention, Identification, and Management of Diffuse Pollution. Van Nostrand Reinhold, New York.

Peet, J. (1992). Energy and the Ecological Economics of Sustainability. Island Press, Washington, D.C.

Somlyódy, L. (1994). Quo Vadis Water Quality Management in Central and Eastern Europe? Water Science and Technology, $30(5), 1-14$.

Somlyódy, L., Alonso, L. R., Fleit, E., Hultman, B., Matsui, S. and Olson, B. H. (1992). Water Quality 2000. A Look at the Main Issues to the End of the Century and How IAWQ Should Respond to Them. IAWQ Yearbook 1992-93, 3-10.

Somlyódy, L., Pintér, J., Koncsos, L., Hanácsek, I. and Juhász, I. (1986). Estimating Averages and Detecting Trends in Water Quality Data. IAHS Publication 157, 61-69.

Stigliani, W.M. (1990). Chemical Emissions from the Processing and Use of Materials: The Need for an Integrated Emissions Accounting System. Ecological Economics, 2, 325-341.

Thomann, R. V. (1972). Systems Analysis and Water Quality Management. McGraw-Hill Book Company, New York.

Thomann, R. V. and Mueller, J. A. (1987). Principles of Surface Water Quality Modeling and Control. Harper and Row, New York.

United Nations (UN), (1989). Prospects of World Urbanisation 1988. Department of International Economic and Social Affairs. Population Studies No. 112, New York.

United States National Research Council (US NRC), (1991). Opportunities in the Hydrologic Sciences. National Academy Press, Washington, D.C.

WCED (1987). Our Common Future: Report of the World Commission on Environment and Development (Brundtland Commission). Oxford University Press, Oxford.

Wetzel, R. G. (1992). Clean Water: a Fading Resource. Hydrobiologia, 243/244, 21-30 
